\title{
Navigation-Assisted Posterior Open Reduction and Internal Fixation in a C-CLAMP Fashion for an Isolated C1 Fracture
}

\author{
Daniele Starnoni ${ }^{1}$ Timo Ecker ${ }^{1}$ Juan Barges-Coll ${ }^{1}$ \\ ${ }^{1}$ Neurosurgical and Spine division, Centre Hospitaliere Universitaire \\ Address for correspondence Juan Barges-Coll, MD, MSc, NCP/SPI, \\ Centre Hospitalier Universitaire Vaudois, Rue de Bugnon 21, \\ Lausanne, Switzerland 1004 (e-mail: juan.barges-coll@chuv.ch).
}

J Neurol Surg B 2021;82(suppl S1):S61-S62.

\begin{abstract}
Keywords

- atlas fracture

- Jefferson fracture

- transverse ligament

- open reduction and internal fixation

C1 fractures with an intact transverse ligament are usually treated conservatively. Patients who present with a progressive diastasis of bone fragments and a progressive articular subluxation mainly attributed to progressive lengthening of the transverse ligament (TAL) fibers can be treated with a C1 "C-clamp" fusion.

A 75-year-old male who sustained a motor vehicle accident was neurologically intact. A computed tomography (CT) imaging demonstrated a jefferson's type-C1 fracture with a slight lateral displacement of the $\mathrm{C} 1$ left lateral mass (LM) and a rotatory subluxation on the right. MRI showed an intact TAL and demonstrated an isolated rupture of the left alar ligament. Conservative treatment was chosen. Radiographic follow-up showed, at 3 months, progressive lateral mass displacement, most likely due to elongation of the TAL fibers; this was also associated with a persistent mechanical neck pain. For this reason, we performed a posterior reduction and internal fixation in a C-clamp fashion by placement of $\mathrm{C} 1$ lateral mass screws and posterior compression sparing the $\mathrm{C} 1-2$ joint. Using navigation, a 3.5-mm screw was inserted into the LM bilaterally. The screw heads were then connected with a rod and compression was applied before tightening. Postoperative CT scan demonstrated a satisfying reduction and further imaging will be made during the follow-up. The patient had a considerable relief of neck pain. Simple lateral mass fixation with C-clamp technique is a reasonable option in case of isolated C1 fractures in patients who have failed conservative management while preserving the range of motion (ROM) at the atlanto-axial joint.

The link to the video can be found at: https://youtu.be/x8bsVwzCt_M.
\end{abstract}

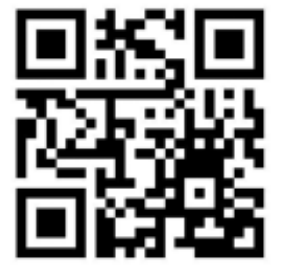

received

March 22, 2019 accepted after revision September 28, 2019 published online March 20, 2020

www.thieme.com/skullbasevideos

www.thieme.com/jnlsbvideos

DOI https://doi.org/ 10.1055/s-0040-1701692. ISSN 2193-6331.

\footnotetext{
(C) 2020. The Author(s).

This is an open access article published by Thieme under the terms of the Creative Commons Attribution-NonDerivative-NonCommercial-License, permitting copying and reproduction so long as the original work is given appropriate credit. Contents may not be used for commercial purposes, or adapted, remixed, transformed or built upon. (https://creativecommons.org/ licenses/by-nc-nd/4.0/) Georg Thieme Verlag KG, Rüdigerstraße 14, 70469 Stuttgart, Germany
} 
S62 Navigation-Assisted Posterior Open Reduction and Internal Fixation Starnoni et al.

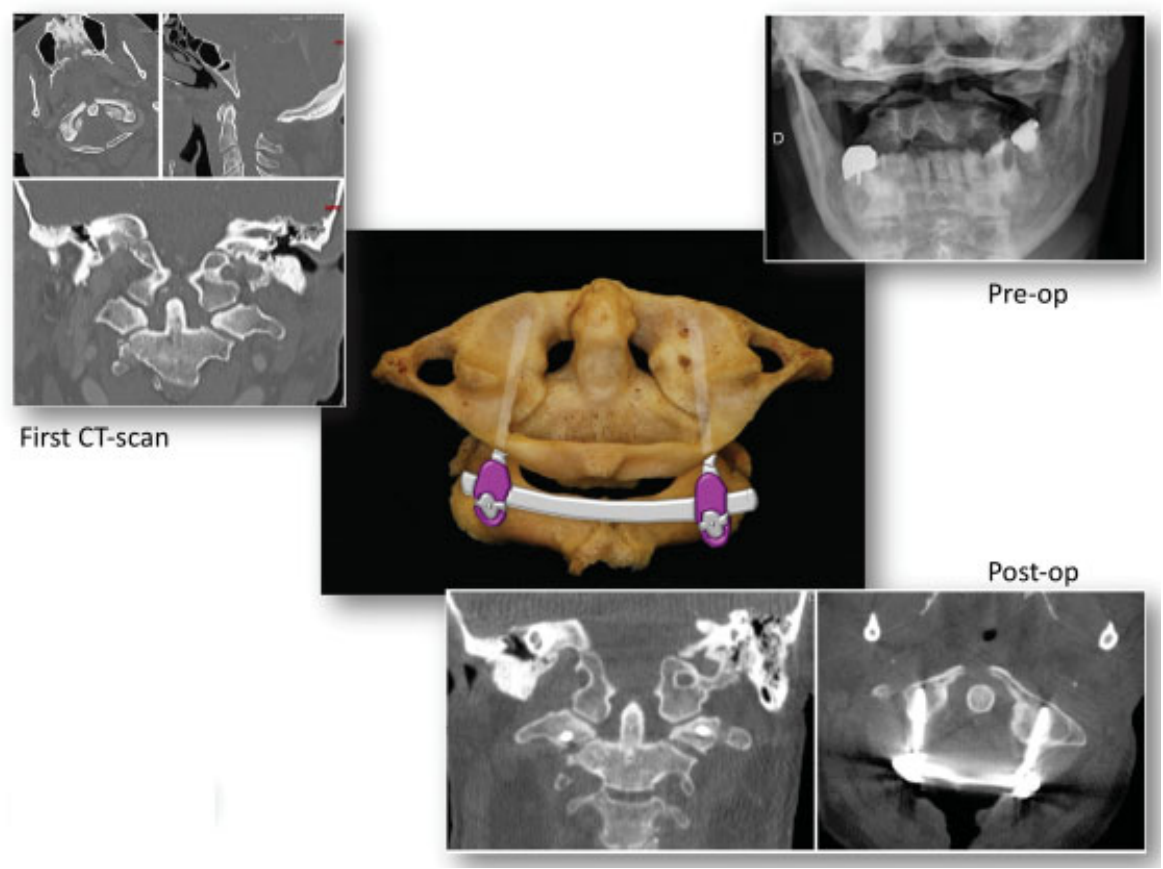

Fig. 1 C1 ORIF in a C-clamp fashion. Pre- and postoperative image and representative model. CT, computed tomography; ORIF, open reduction and internal fixation.

Conflict of Interest

None declared. 